\title{
Fruit Set and Yield Patterns in Six Capsicum Cultivars
}

\author{
A. Maaike Wubs and Yuntao Ma ${ }^{1,2}$ \\ Horticultural Supply Chains Group, Wageningen University, P.O. Box 630, \\ 6700 AP Wageningen, The Netherlands; and Biometris, Wageningen \\ University, P.O. Box 100, 6700 AC Wageningen, The Netherlands
}

\section{Lia Hemerik \\ Biometris, Wageningen University, P.O. Box 100, 6700 AC Wageningen, The Netherlands}

\section{Ep Heuvelink}

Horticultural Supply Chains Group, Wageningen University, P.O. Box 630, 6700 AP Wageningen, The Netherlands

Additional index words. Capsicum annuum, cultivar comparison, fruit size, source strength, sink strength

\begin{abstract}
Fruit set and yield patterns were studied in detail in six pepper cultivars. Fruit set differed largely between the cultivars: cultivars with small fruits (fruit fresh weight 20 to $40 \mathrm{~g}$ ) showed higher fruit set $(\approx 50 \%)$ than cultivars with large fruits (fruit fresh weight 120 to $200 \mathrm{~g} ; \mathbf{1 1 \%}$ to $19 \%$ ). The former showed continuous fruit set (four to five fruits/ plant/week), whereas the latter showed fluctuations in fruit set. Fluctuations in weekly fruit set, expressed as the ratio between standard deviation of weekly fruit set and the mean of weekly fruit set (Cv), were much lower for the cultivars with small fruits $(0.44$ to 0.49) than for the cultivars with large fruits (1.1 to 1.6). Fluctuations in weekly fruit yield varied between 0.51 and 0.77 for cultivars with small fruits and between 1.04 and 1.45 for cultivars with large fruits. Fluctuations in fruit yield were significantly positively correlated (Pearson $R=\mathbf{0 . 8 7}$ ) with fluctuations in fruit set. The correlation between fruit set and fruit yield patterns was highest with a lag time of 8 weeks for the cultivars with small fruits and 9 to $\mathbf{1 0}$ weeks for the cultivars with large fruits. This corresponds with the expected lag time based on the average fruit growth duration. The cultivars produced the same amount of biomass, implying that source strength was more or less similar. Hence, differences in fruit set and fruit yield patterns between the cultivars were not the result of differences in source strength and must therefore be related to differences in sink strength.
\end{abstract}

Flower and fruit abortion is a yield-limiting factor in many crops (Bacci et al., 2006; Goldschmidt, 1999; Halbrecq et al., 2005). Abortion can be caused by unfavorable conditions such as temperature stress (Guilioni et al., 1997), low light conditions (low source strength; Aloni et al., 1996), or limited pollination (Berjano et al., 2006). Also, under nonstressed conditions, sweet pepper flowers

Received for publication 10 Feb. 2009. Accepted for publication 12 Apr. 2009.

The experiment was funded by the Wellensiek fund; the graduate school PE\&RC (Wageningen University) financially supported Maaike Wubs and Yuntao Ma.

We thank Gerrit Gort for assisting with the application of linear mixed models and Leo Marcelis and Jaap Molenaar for critically reading the manuscript.

${ }^{1}$ Current addresses: Key Laboratory of Plant-Soil Interactions, Ministry of Education, College of Resources and Environment, China Agricultural University, Beijing 100094, China; and LIAMA, Institute of Automation, Chinese Academy of Sciences, Beijing 100080, China.

${ }^{2}$ To whom reprint requests should be addressed; e-mailyuntao.ma@cau.edu.cn. and young fruits abort as a result of competition for assimilates with fast-growing fruits (strong sinks; Heuvelink et al., 2004). Sweet pepper plants show an indeterminate growth pattern, which means that flowers are produced continuously. Together with the abortion of flowers and young fruits resulting from competition with fast-growing fruits, this leads to alternating periods of high and low fruit set. These fluctuations in fruit set are believed to be the cause of cyclic fluctuations in fruit yield. Irregular fruit yield causes difficulties in the planning of activities throughout the production chain of sweet peppers and, as sweet pepper crops of different growers are synchronized, it causes fluctuations in the price of sweet peppers as well (Gottschall, 2001).

Sweet pepper cultivars are known to differ in fruit set percentage, especially under heat or light stress. Aloni et al. (1996) and Turner and Wien (1994) observed differences in level of flower abortion between several cultivars, whereas Shifriss et al. (1994) found fruit set differences in different accessions under shading circumstances. However, fruit set was observed over a short time and patterns over time were not reported. Just a few examples of detailed patterns of fruit set within the plant are given, e.g., cucumber (Marcelis, 1992), Salomon's seal (Guitián et al., 2001), and maize (Reed and Singletary, 1989). Cultivar comparisons in fruit set are more abundant, e.g., pumpkin (Stapleton et al., 2000), apricots (Alburquerque et al., 2002), grapevine (Lebon et al., 2004), and eggplant (Passam and Khah, 1992). Egli and Bruening (2006) compared detailed fruit set patterns between two soybean cultivars. Detailed characterization of fruit set and yield patterns and investigation of reasons underlying cultivar differences in these patterns for pepper have not been done so far. Because fluctuations in sweet pepper fruit set and fruit yield are a problem for the grower as well as for the rest of the production chain, analysis of this problem is necessary.

This article aims at characterizing and analyzing differences among six pepper cultivars in fruit set and yield patterns. It was investigated whether fruit set fluctuations are indeed the cause of yield fluctuations. We elucidate on whether different fruit set patterns for different cultivars result from genotypic differences in source or sink strength.

\section{Materials and Methods}

Experimental setup. Seeds from six pepper cultivars (Capsicum annuum L.) differing in fruit size (20 to $205 \mathrm{~g}$ fresh weight; Table 1) were obtained from De Ruiter Seeds (Bergschenhoek, The Netherlands). Seeds were sown on $1 \mathrm{Feb}$. in potting soil and after $10 \mathrm{~d}$, seedlings were transferred into rockwool cubes. On 30 Mar. (when the first flower buds were appearing), plants were transferred to a $150-\mathrm{m}^{2}$ greenhouse compartment of a multispan Venlo-type greenhouse in Wageningen, The Netherlands $\left(52^{\circ} \mathrm{N}\right)$ and placed on rockwool slabs at a density of 3.8 plants/ $\mathrm{m}^{2}$. Heating set point was $18 / 15{ }^{\circ} \mathrm{C}$ (day/ night, length of day depended on sunset and sunrise) and ventilation set point was $1{ }^{\circ} \mathrm{C}$ above heating set point. Temperature and relative humidity were recorded every 5 min using a commercial computer system (Hoogendoorn, Vlaardingen, The Netherlands). Realized average daily air temperature over the total growth period (30 Mar. to 30 Aug.) was $21.6 \pm 2.0{ }^{\circ} \mathrm{C}$ (mean $\pm \mathrm{sD}$ ); average humidity was $77 \% \pm 10 \%$ (mean \pm SD). Irrigation was done with a standard nutrient solution for sweet pepper (BLGG, Naaldwijk, The Netherlands) with electrical conductivity $2.5 \mathrm{dS} \cdot \mathrm{m}^{-1}$ and $\mathrm{pH}$ 5.5. No $\mathrm{CO}_{2}$ enrichment was applied. Daily global radiation outside the greenhouse was recorded at an official weather station at $\approx 300 \mathrm{~m}$ distance. The average global radiation outside the greenhouse during the total growth period was $16.3 \pm 5.6 \mathrm{MJ} / \mathrm{m}^{-2} \cdot \mathrm{d}^{-1}$ (mean $\left.\pm \mathrm{SD}\right)$. Plants were pruned to two main stems with the weakest branch of each dichotomous split pruned above the first flower and leaf.

A randomized complete block design was applied with three blocks and six plots per block, each plot containing one cultivar. A plot consisted of 20 plants in a double row. 
Table 1. Cultivar names, their type, and their fresh fruit weight as indicated by the breeder (De Ruiter Seeds, Bergschenhoek, The Netherlands).

\begin{tabular}{llc}
\hline $\begin{array}{l}\text { Cultivar (g fresh } \\
\text { weight/fruit) }\end{array}$ & \multicolumn{1}{c}{ Type } & Fruit wt \\
\hline Medina & Hot pepper & 20 \\
Fireflame & Hot pepper & 20 \\
Furila & Hot pepper & 45 \\
Gepetto & Pointed sweet & 135 \\
& $\quad$ pepper \\
Nazar & Block-shaped & 140 \\
& $\quad$ sweet pepper \\
Funky & Block-shaped \\
& sweet pepper & 205 \\
\hline
\end{tabular}

Eight plants in each plot were used for destructive harvests. Guard plants were placed between plants used for destructive harvest and between the plots in the same row. In addition to the three blocks, there was an extra double row with six plots, each plot containing 10 plants of one cultivar. This double row was considered the fourth block in the analysis of fruit set, fruit yield, fruit weight, and fruit growth duration.

Observations and destructive measurements. A total of 12 plants per cultivar were used for observations of flowering, abortion, and fruit harvest dates. Six of these plants came from the extra double row (Block 4), whereas the other six plants had been grown in the larger plots (two plants per block for each cultivar). Flowering and abortion dates were recorded six times a week. The week of fruit set was the week in which the flower reached anthesis. A fruit was defined to have been set if it eventually reached the harvestable stage or survived more than 10 (cultivars with small fruits) or $20 \mathrm{~d}$ (cultivars with large fruits). Completely red fruits were harvested and their fresh and dry weights were measured. This fruit harvest was done every Tuesday and Friday.

For each cultivar, five destructive harvests were done. The first destructive harvest occurred when the plants were placed on the slabs. At each of the four following harvests, six plants per cultivar (two from each block) were harvested. The harvest dates differed between the cultivars, because their elongation rates were different and cultivation had to be stopped when plants reached the top wire in the greenhouse. Leaf area was measured with a leaf area meter (LI-3100; LiCOR, Lincoln, NE); and fresh and dry weight of leaves, stems, and fruits of each plant were determined. Leaves and stems were dried for $12 \mathrm{~h}$ in a ventilated oven at $105^{\circ} \mathrm{C}$, whereas fruits were dried for two cycles of $12 \mathrm{~h}$ at this temperature. Roots were not measured. To each harvested plant, the weight of the already harvested fruits from that plant was added to obtain total plant weight and total fruit weight.

Calculation of desired variables. Percentage fruit set was calculated as the number of set fruits divided by the number of flowers $\times 100$. In 'Funky', 'Nazar', and 'Gepetto', some buds aborted before flowering; they are included in the number of flowers in the calculation of percentage fruit set. Weekly fruit set (number of fruits/plant/week) was calculated as the number of fruits that set within a calendar week. Weekly fruit yield was the total number of harvested fruits or the total harvested fruit weight of the two harvests in a calendar week. Fluctuations in weekly fruit set were quantified by the $\mathrm{CV}$ (= SD/mean). CV for fruit set was calculated from the SD of the weekly fruit set (number of fruits/plant/week) and the mean of the weekly fruit set. Similar calculations were done for fruit yield, expressed in number of fruits (number of fruits/plant/week) or in fruit weight (g dry weight/plant/week). All cVs were calculated per plant for the 12 observational plants per cultivar. To be able to compare fluctuations in fruit set and yield between the cultivars, the cvs were calculated over the period in which all cultivars were present: Week 15 to 28 for fruit set and Week 24 to 29 for fruit yield. For the harvested fruits, fruit growth duration was calculated as the time between fruit set and fruit harvest. For the aborted fruits, the survival time was calculated as the time between flowering and abortion.

Statistical analyses. Percentage fruit set, Cvs of fruit set and fruit yield, individual fruit weight (fresh and dry), and fruit growth duration were compared between the cultivars based on the data until day 206 (Week 29 ) of the 12 observational plants per cultivar. Individual fruit weight and fruit growth duration were averaged for each plant before analysis. Leaf area per plant, total fresh and dry plant weights, and partitioning of dry matter into the fruits were compared between the cultivars in Week 29 (Days 200 to 206) based on the six harvested plants per cultivar in that week. Analyses were done with linear mixed models with cultivar as the fixed factor and cultivar nested within the block as the error term. Fruit weight, the cvs, and leaf area were allowed to have different SDs per cultivar to avoid trends in the residuals. Fruit set and dry matter partitioning into the fruits were analyzed as fractions. These fractions were arcsine transformed before analysis to obtain normally distributed data (Sokal and Rohlf, 1994). If the cultivar effect was significant, differences between cultivars were tested with contrasts.

Timing of fruit abortion of the different cultivars was compared by means of Kaplan-

Table 2. Fruit set, number of set and harvested fruits, and fruit yield are given for the six cultivars together with their $\mathrm{CV}(\mathrm{CV}=$ sD/average $){ }^{\mathrm{z}}$

\begin{tabular}{|c|c|c|c|c|c|c|c|}
\hline \multirow[b]{3}{*}{ Cultivar } & \multirow{3}{*}{$\begin{array}{c}\text { Fruit set } \\
(\%)\end{array}$} & \multirow{2}{*}{\multicolumn{2}{|c|}{$\begin{array}{c}\text { Fruit set } \\
\text { (number/plant/week) }\end{array}$}} & \multicolumn{4}{|c|}{ Fruit yield } \\
\hline & & & & \multicolumn{2}{|c|}{ (number/plant/week) } & \multicolumn{2}{|c|}{ (g dry weight/plant/week) } \\
\hline & & Avg & $\mathrm{CV}$ & Avg & $\mathrm{CV}$ & Avg & $\mathrm{CV}$ \\
\hline$\overline{\text { Medina }}$ & $59 \mathrm{~d}^{\mathrm{y}}$ & $4.99 \mathrm{~d}$ & $0.45 \mathrm{a}$ & $3.88 \mathrm{~d}$ & $0.55 \mathrm{a}$ & $9.6 \mathrm{~b}$ & $0.51 \mathrm{a}$ \\
\hline Fireflame & $52 \mathrm{c}$ & $4.87 \mathrm{~d}$ & $0.49 \mathrm{a}$ & $4.61 \mathrm{e}$ & $0.58 \mathrm{a}$ & $11.3 \mathrm{~b}$ & $0.58 \mathrm{a}$ \\
\hline Furila & $52 \mathrm{c}$ & $3.82 \mathrm{c}$ & $0.44 \mathrm{a}$ & $2.99 \mathrm{c}$ & $0.74 \mathrm{~b}$ & $11.4 \mathrm{~b}$ & $0.77 \mathrm{~b}$ \\
\hline Gepetto & $19 \mathrm{~b}$ & $1.36 \mathrm{~b}$ & $1.09 \mathrm{~b}$ & $1.26 \mathrm{~b}$ & $1.06 \mathrm{c}$ & $13.6 \mathrm{c}$ & $1.04 \mathrm{c}$ \\
\hline Nazar & $19 \mathrm{~b}$ & $1.26 \mathrm{~b}$ & $1.19 \mathrm{~b}$ & $1.21 \mathrm{~b}$ & $1.37 \mathrm{~d}$ & $10.7 \mathrm{~b}$ & $1.42 \mathrm{~d}$ \\
\hline Funky & $11 \mathrm{a}$ & $0.69 \mathrm{a}$ & $1.54 \mathrm{c}$ & $0.56 \mathrm{a}$ & $1.39 \mathrm{~d}$ & $7.4 \mathrm{a}$ & $1.45 \mathrm{~d}$ \\
\hline
\end{tabular}

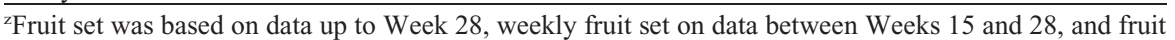
yield was based on data from Weeks 24 to 29 .

${ }^{y}$ Different letters within the same column indicate significant differences $(\alpha=0.05)$ obtained with contrasts $(\mathrm{n}=12)$.
Meijer survival analysis (Kleinbaum and Klein, 2005). In survival analysis, the times to an event of interest are analyzed. In this case, abortion of fruits is the event of interest and the survival time is the time between flowering and abortion. Fruits that do not abort but cannot be observed any more (harvested fruits, unripe fruits at the end of the experiment) have a censored survival time; abortion was not observed before this time, but in theory, it can still happen. The final value of the survival curve is the fraction of the total number of flowers that did not abort: harvested fruits or fruits that were still growing by the end of the observational period. This method in survival analysis produces a curve indicating which proportion of the fruits is still surviving at a certain time after anthesis. Using a log rank test, survival curves were compared among the six cultivars for the period in which all of these were grown (up to Day 206).

To compare fluctuations in fruit set with fluctuations in fruit yield (both in number of fruits/plants/week) for each cultivar, the Cvs for fruit set and fruit yield were correlated using Pearson's correlation coefficient. In this case, fruit set in each plant was calculated from the first week of fruit set until the week when the last harvested fruits of the cultivar were set and fruit yield from the first week of fruit yield in each plant until the last week of fruit yield of the cultivar. To determine whether the pattern in fruit yield is the lagged pattern of fruit set, correlations between the number of set fruits and the number of harvested fruits were made for different lag times.

All statistical analyses were done in $\mathrm{R}$ 2.6.0 (R Development Core Team, 2007).

\section{Results}

Fruit set. Fruit set percentage differed between the cultivars $(P<0.001$; Table 2$)$. Fruit set percentages of 'Fireflame' and 'Medina' differed, although the total number of set fruits was similar, caused by a higher number of flowers produced in Fireflame plants (data not shown). Average weekly fruit set was higher for the small-fruited cultivars Medina, Fireflame, and Furila compared with the large-fruited cultivars Gepetto, Nazar, and Funky (Table 2; Fig. 1). The large-fruited cultivars showed a wave-like 
pattern with simultaneously timed peaks around Weeks 15 and 16, 21, 24, and 30 (intervals of 3 to 6 weeks). The small-fruited cultivars also showed waves in fruit set, but for these, the period appeared to be only 2 to 3 weeks. Fruit set started 1 week later for the large-fruited cultivars than for the smallfruited ones. Average weekly fruit set decreased with increasing fruit size, whereas the extent of the fluctuations (CV) increased with increasing fruit size (Table 2).

The survival curves (fraction nonaborted fruits after anthesis) (Fig. 2) showed an initial decrease in the survival of the young fruits, but this leveled off earlier for the smallfruited cultivars (15 d after anthesis) than for the large-fruited cultivars (25 d after anthesis). Survival of the large-fruited cultivars (Funky, Nazar, and Gepetto) started below one, because part of the buds aborted before anthesis. Survival curves of 'Fireflame' and 'Furila' were not significantly different from each other $(P=0.11)$ as were the curves of 'Gepetto' and 'Nazar' $(P=0.99)$. All other survival curves were significantly different $(P<0.001)$.

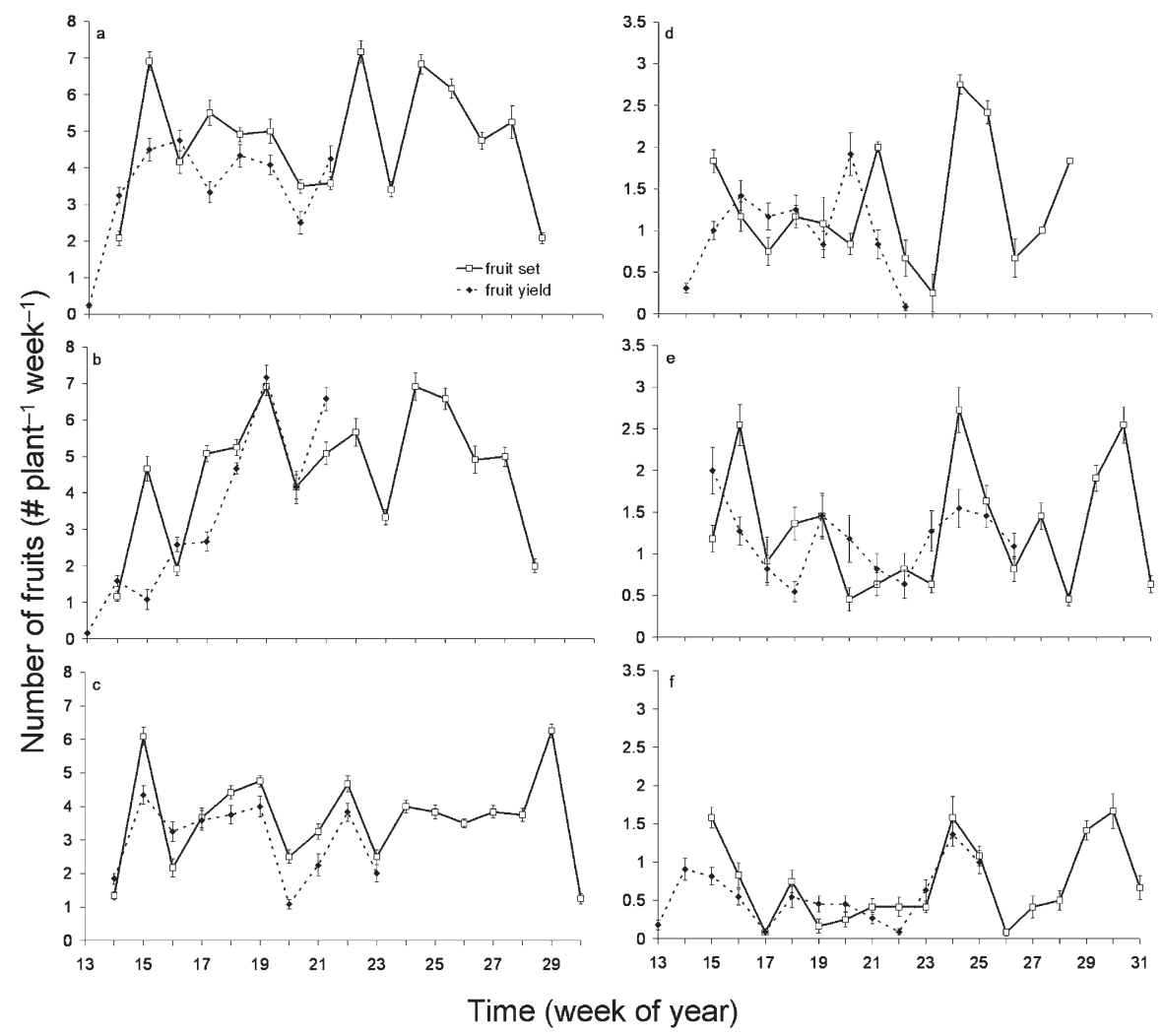

Fig. 1. Patterns of weekly fruit set (open symbols and continuous line) and weekly fruit yield (closed symbols and dashed line) (both in number of fruits/plant/week) for the six cultivars: (A) Medina, (B) Fireflame, (C) Furila, (D) Gepetto, (E) Nazar, and (F) Funky. To compare time patterns, the times at which fruits were harvested were brought forward 8 weeks (A-C), 9 weeks (D-E), or 10 weeks (F). Error bars indicate SE $(\mathrm{n}=12)$.

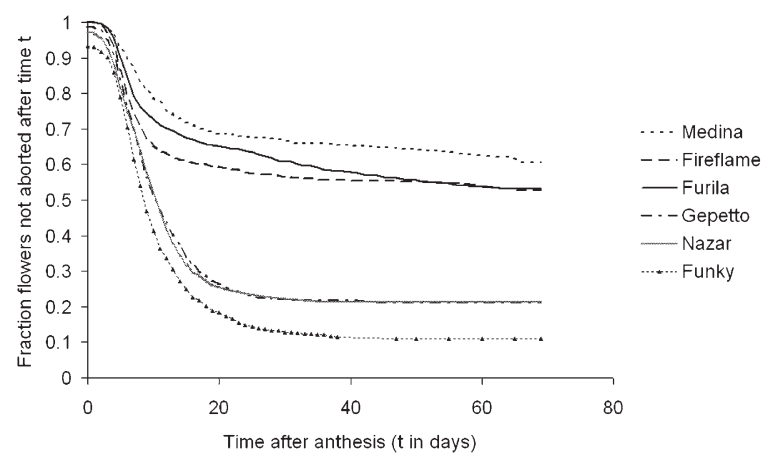

Fig. 2. Survival curves of fruits for the six cultivars. The survival time of a fruit is the time from flowering to abscission. Lines represent the population averages of survival times. Survival curves of 'Gepetto', 'Nazar', and 'Funky' start below one, because a number of the buds aborted before flowering. Survival is based on data from the start of the experiment, Day 89, up to Day 206.
Fruit yield. The quantity and timing of the number of harvested fruits differed between the cultivars (Fig. 1). After an initial increase, a considerable number of fruits was harvested weekly for the small-fruited cultivars Medina, Fireflame, and Furila. Fruit harvest for the large-fruited cultivars Nazar, Gepetto, and Funky started 2 weeks later (Fig. 1) and the number of harvested fruits per plant was lower in these cultivars than for the cultivars with small fruits (Table 2; Fig. 1). Although the numbers harvested per plant per week differed largely among the cultivars, the harvested dry weight per plant per week was much more similar (Table 2). Dry weight of harvested 'Fireflame' fruits increased up to Week 27, whereas 'Medina' and 'Furila' had a more regular fruit yield (Fig. 3A). Fluctuations in harvested dry weight of the largefruited cultivars were clearer than in number of harvested fruits (Figs. 1 and 3B), also reflected in a higher $\mathrm{CV}$ for the harvested dry weight (Table 2). Three peaks in fruit yield were registered for 'Funky' and 'Nazar'. The first two peaks were almost at the same time, but the last one was 1 week earlier for 'Nazar' than for 'Funky'. Fluctuations in fruit yield in cultivar Gepetto had a different periodicity than for 'Nazar' and 'Funky' (Figs. 1 and 3B).

The $\mathrm{CV}$ for yield in Weeks 24 to 29 (number of fruits/plant/week and g dry weight/plant/ week) was significantly higher when fruit size was higher (Table 2). The range of $\mathrm{CV}$ values between the cultivars was smaller for fruit yield than for fruit set.

Relation between fruit set and fruit yield. The fluctuations in fruit yield (number of fruits/plant/week) were strongly and positively correlated to fluctuations in fruit set (Pearson $R=0.87, P<0.001$; Fig. 4). When the average fruit growth durations in days (Table 3) were converted to weeks, the peak in yield of the cultivars with large fruits was expected to be 9, 9.4, and 9.8 weeks after fruit set for 'Gepetto', 'Nazar', and 'Funky', respectively. This was confirmed by correlations between fruit set and yield (both per plant) with a range of lag times. Most plants of these cultivars had a significant correlation when the lag was 9 or 10 weeks (Table 4), although weaker correlations appeared at Week 8 and some plants had no correlation between fruit set and fruit yield at any lag time. Correlations were on average 0.79 . The correlation was less clear when average fluctuations of fruit set and fruit yield were compared graphically (Fig. 1D-F). For the small-fruited cultivars, correlation between number of set fruits and number of harvested fruits was highest around 8 weeks, the week expected based on average fruit growth duration, but the number of plants with a significant correlation was low. The graphic comparison of fruit set and fruit yield in these cultivars revealed that the average patterns showed strong similarities (Fig. 1A-C).

Fruit characteristics. As expected, average individual fruit fresh and dry weights of the cultivars differed from each other $(P<$ 0.001 ; Table 3 ); only the cultivars Medina 


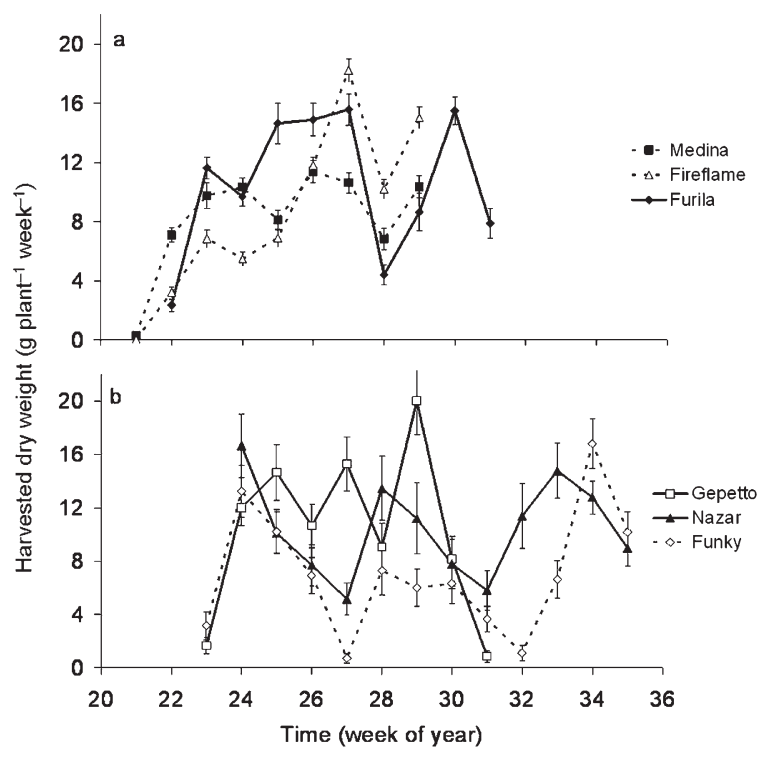

Fig. 3. Weekly fruit yield (g dry weight/plant/week) for the cultivars with small fruits (A) and large fruits (B). Error bars indicate SE $(\mathrm{n}=12)$.

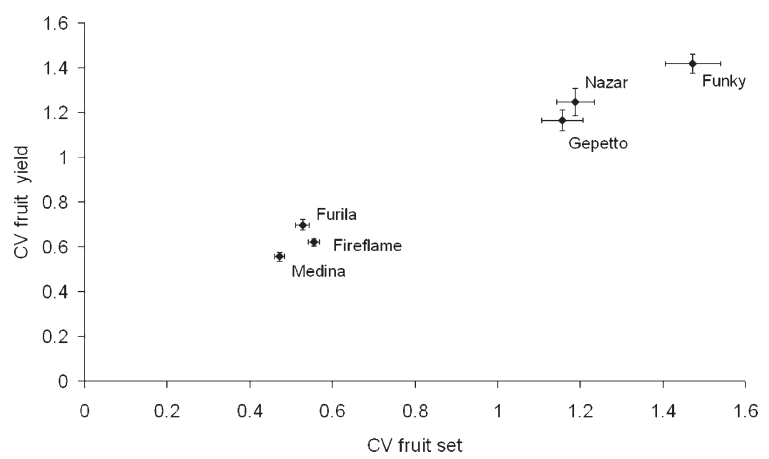

Fig. 4. Average Cv for weekly fruit yield plotted against average cv for weekly fruit set (both in number plants/week) for the six cultivars. Error bars indicate SE $(n=12)$.

Table 3. Average individual fruit fresh and dry weights of harvested fruits, fruit growth duration, and plant cumulative dry weight, fresh weight, leaf area, and fraction dry matter partitioned to the fruits up to Week 29 for the six pepper cultivars.

\begin{tabular}{|c|c|c|c|c|c|c|c|}
\hline \multirow[b]{2}{*}{ Cultivar } & \multicolumn{2}{|c|}{ Fruit wt } & \multirow[b]{2}{*}{$\begin{array}{l}\text { Fruit growth } \\
\text { duration (days) }\end{array}$} & \multirow[b]{2}{*}{$\begin{array}{c}\text { Plant dry } \\
\text { wt (g/plant) }\end{array}$} & \multirow[b]{2}{*}{$\begin{array}{l}\text { Plant fresh } \\
\text { wt (g/plant) }\end{array}$} & \multirow[b]{2}{*}{$\begin{array}{l}\text { Plant leaf area } \\
\left(\mathrm{cm}^{2} / \text { plant }\right)\end{array}$} & \multirow[b]{2}{*}{$\begin{array}{l}\text { Dry matter ir } \\
\text { fruits }(\%)\end{array}$} \\
\hline & $\begin{array}{l}\text { fresh } \\
\text { (g fruit) }\end{array}$ & $\begin{array}{c}\text { dry } \\
\text { (g fruit) }\end{array}$ & & & & & \\
\hline Medina & $19 \mathrm{a}^{\mathrm{z}}$ & $2.4 \mathrm{a}$ & $57 \mathrm{a}$ & $220 \mathrm{a}$ & $1,640 \mathrm{a}$ & $7,525 \mathrm{a}$ & $52 \mathrm{~d}$ \\
\hline Fireflame & $18 \mathrm{a}$ & $2.3 \mathrm{a}$ & $58 \mathrm{a}$ & $258 \mathrm{a}$ & $1,806 \mathrm{a}$ & $7,865 \mathrm{a}$ & $49 \mathrm{~cd}$ \\
\hline Furila & $36 \mathrm{~b}$ & $3.6 \mathrm{~b}$ & $58 \mathrm{a}$ & $258 \mathrm{a}$ & $2,244 \mathrm{~b}$ & $10,370 \mathrm{~b}$ & $52 \mathrm{~d}$ \\
\hline Gepetto & $129 \mathrm{~d}$ & $10.8 \mathrm{~d}$ & $63 \mathrm{~b}$ & $274 a$ & $2,528 \mathrm{c}$ & $15,192 \mathrm{c}$ & $35 \mathrm{a}$ \\
\hline Nazar & $119 \mathrm{c}$ & $8.9 \mathrm{c}$ & $66 \mathrm{c}$ & $253 \mathrm{a}$ & $2,864 \mathrm{~d}$ & $15,282 \mathrm{c}$ & $47 \mathrm{c}$ \\
\hline Funky & $199 \mathrm{e}$ & $13.6 \mathrm{e}$ & $69 \mathrm{~d}$ & $244 \mathrm{a}$ & $2,623 \mathrm{~cd}$ & $14,440 \mathrm{c}$ & $40 \mathrm{~b}$ \\
\hline
\end{tabular}

${ }^{\mathrm{z}}$ Different letters within the same column indicate significant differences $(\alpha=0.05)$ obtained with contrasts ( $\mathrm{n}=12$ for fruit characteristics, $\mathrm{n}=6$ for plant characteristics).

and Fireflame were not significantly different in fruit fresh and dry weights. There was no change in average fruit weight during the experiment (data not shown). Fruit growth duration differed significantly among the cultivars $(P<0.001$; Table 3$)$. 'Medina', 'Fireflame', and 'Furila' showed the same fruit growth duration, whereas 'Nazar', 'Gepetto', and 'Funky' had significantly longer fruit growth durations.
Total plant growth and development. At least up to Day 180, there was no clear difference in dry matter production between the cultivars (Fig. 5A), but there was in leaf area (Fig. 5B). The cultivars with the smallest sized fruits ('Medina' and 'Fireflame') had a lower leaf area than 'Furila', which in turn had a lower leaf area than the large-fruited cultivars. In Week 29 (Days 200 to 206), the differences among the cultivars were not
Table 4. Number of plants with a significant positive correlation between fruit set and fruit yield. $^{\mathrm{z}}$

\begin{tabular}{lccccccc}
\hline $\begin{array}{l}\text { Lag time } \\
\text { (weeks) }\end{array}$ & 6 & 7 & 8 & 9 & 10 & 11 & 12 \\
\hline Medina & 0 & 0 & 3 & 1 & 0 & 0 & 0 \\
Fireflame & 1 & 1 & 6 & 2 & 0 & 0 & 0 \\
Furila & 0 & 0 & 5 & 0 & 0 & 1 & 0 \\
Gepetto & 0 & 0 & 1 & 3 & 1 & 0 & 0 \\
Nazar & 0 & 0 & 1 & 4 & 2 & 0 & 0 \\
Funky & 0 & 0 & 0 & 1 & 6 & 1 & 0 \\
\hline
\end{tabular}

${ }^{2}$ The time series of weekly number of set fruits and the time series of weekly number of harvested fruits were correlated at a given lag time (weeks) $(\mathrm{n}=12)$.

significant for total plant dry weight $(P=$ 0.11 ; Table 3$)$, but they were for leaf area and total plant fresh weight $(P<0.001$; Table 3$)$. The small-fruited cultivars had a lower plant fresh weight. Fraction dry weight partitioned into the fruits up to Week 29 was also significantly different among the cultivars $(P<0.001$; Table 3). For 'Medina', 'Fireflame', 'Furila', and 'Nazar', dry matter partitioning to the fruits was $\approx 50 \%$, whereas 'Gepetto' and 'Funky' showed a lower partitioning to the fruits ( $35 \%$ to $40 \%)$. This difference was consistent during the whole cultivation period.

\section{Discussion}

Characterizing and analyzing cultivar differences in fruit set and yield patterns and relating fruit yield to fruit set patterns was the objective of this study. Small-fruited cultivars have much smaller relative fluctuations in fruit set and fruit yield than large-fruited cultivars. Both fruit set and yield patterns showed fluctuations, and the extent of the fluctuations in fruit yield was strongly positively correlated to fluctuations in fruit set (Fig. 4). The expected lag time between fruit set and fruit yield, i.e., the average growth duration ( 8 weeks for the small-fruited and 9 to 10 weeks for the large-fruited cultivars), was confirmed as well (Fig. 1; Table 4). Hence, fluctuations in fruit yield are indeed primarily caused by fluctuations in fruit set. The extent of the fluctuations in fruit yield were not the same as the fluctuations in fruit set: the small-fruited cultivars and 'Nazar' had more fluctuation in fruit yield than in fruit set, whereas fluctuations in 'Funky' were slightly smaller in fruit yield than in fruit set. This could be the result of small variations in fruit growth period and/or variations in harvest stage. With regard to the timing of fruit abortion, this was related to the fruit growth duration, because the period after flowering during which fruits could abort is longer for the cultivars with longer fruit growth duration (Fig. 2).

Biomass production over time was similar for all cultivars. When biomass production is taken as a measure for source strength, it implies that the differences in fruit set among the cultivars are not caused by differences in source strength. Day-to-day variations in radiation resulted in similar changes in 


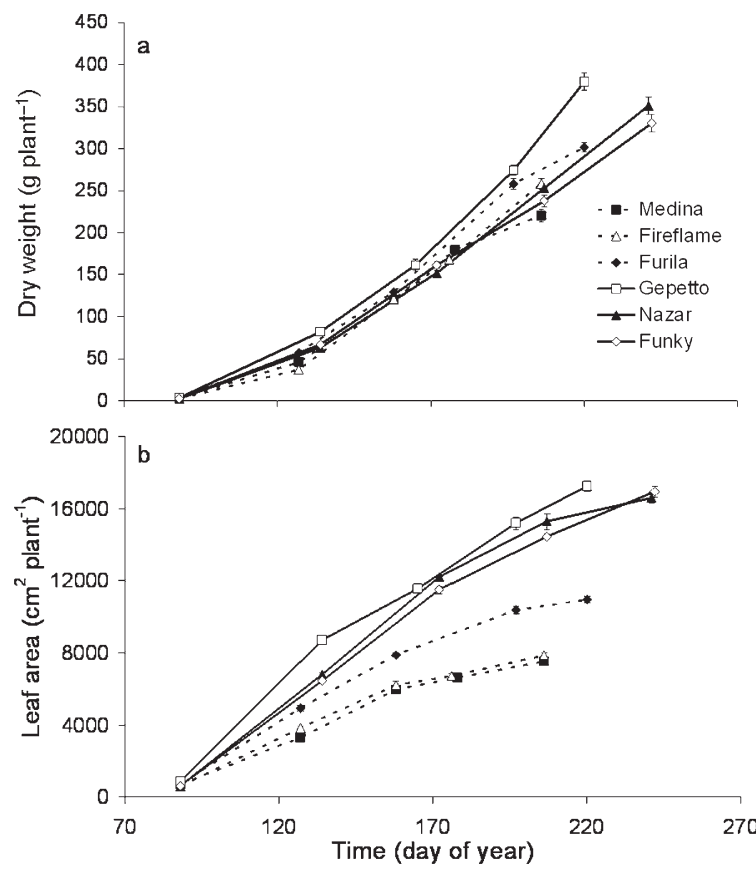

Fig. 5. Total aboveground biomass (A, $g$ dry weight/plant) and leaf area $\left(\mathbf{B}, \mathrm{cm}^{2} /\right.$ plant $)$ for the six cultivars for each destructive harvest. Error bars indicate SE $(n=6)$.

source strength for all the cultivars. Inspection of weekly fruit set and weekly average radiation revealed no clear influence of average radiation on fruit set. Fruit set in sweet pepper is known to depend on competition from fast-growing fruits (Marcelis et al., 2004). As more fruits set, sink strength increases and reduces fruit set of subsequent flowers. When the fruits are nearly ripe, new flowers can set fruit (Heuvelink et al., 2004). This resulted in fluctuations in fruit set for the cultivars with large fruits ('Gepetto', 'Nazar', and 'Funky'), but not for the cultivars with small fruits. Fluctuations in fruit set in the cultivars with small fruits were relatively low (low CV), although fast-growing fruits were always present. Cultivars with small fruits producing higher numbers of fruits than cultivars with large fruits were also observed in cucumber (Jasso-Chaverria et al., 2005) and pumpkin (Stapleton et al., 2000). The larger fruit weight in cultivars with large fruits was not primarily caused by a difference in fruit growth duration, because this was small compared with the differences in fruit weight (Table 3). Differences in fruit size must therefore be caused by differences in fruit growth rate, which can differ between cultivars (Amorós et al., 2003; Cheng and Breen, 1992; Zhang et al., 2005). Higher fruit size and fruit growth rate can be related to higher fruit sink strength (potential fruit growth rate; Marcelis, 1996), but the fruit sink strength of the different cultivars is not yet known. Because source strength for the different cultivars was more or less similar, differences in fruit sink strength between the cultivars are the most likely explanation for different fruit set patterns in the cultivars. Lower sink strength per fruit would imply that more fruits can set, which is seen in the present experiment.
The similarity in total biomass production is remarkable, because leaf area vastly differed between the cultivars. Differences in plant architecture and plant height among the cultivars could explain this. The cultivars with small fruits had a more open canopy, which is favorable for light penetration and light interception lower in the canopy (Sassenrath-Cole, 1995). The cultivars with small fruits grew also much stronger in height, thereby causing shade for the adjacent cultivars with large fruits. This resulted in higher light interception for the former than what would have occurred in a homogeneous crop, whereas the latter received less light than in a homogeneous crop. In a homogeneous crop, fruit set would have been higher in the large-fruited cultivar and lower in the small-fruited cultivars.

In conclusion, fruit set in Capsicum cultivars did differ in the percentage fruit set with higher fruit set in cultivars with small fruits resulting in a more homogeneous fruit set in time (less fluctuations). Fluctuations in fruit yield could be explained from the fluctuations in fruit set, because magnitude of both fluctuations was strongly positively correlated and the lag time between fruit set and fruit yield was as expected from the average fruit growth duration. Differences in fruit set patterns among cultivars were not caused by differences in source strength, but were probably the result of differences in fruit sink strength.

\section{Literature Cited}

Alburquerque, N., L. Burgos, and J. Egea. 2002. Variability in the developmental stage of apricot ovules at anthesis and its relationship with fruit set. Ann. Appl. Biol. 141:147152.
Aloni, B., L. Karni, Z. Zaidman, and A.A. Schaffer. 1996. Changes of carbohydrates in pepper (Capsicum annuum L.) flowers in relation to their abscission under different shading regimes. Ann. Bot. (Lond.) 78:163-168.

Amorós, A., P. Zapata, M.T. Pretel, M.A. Botella, and M. Serrano. 2003. Physico-chemical and physiological changes during fruit development and ripening of five loquat (Eriobotrya japonica Lindl.) cultivars. Food Sci. Technol. Intl. 9:43-49.

Bacci, L., M.C. Picanço, A.H.R. Gonring, R.N.C. Guedes, and A.L.B. Crespo. 2006. Critical yield components and key loss factors of tropical cucumber crops. Crop Prot. 25:11171125.

Berjano, R., C. De Vega, M. Arista, P.L. Ortiz, and S. Talavera. 2006. A multi-year study of factors affecting fruit production in Aristolochia paucinervis (Aristolochiaceae). Amer. J. Bot. 93: 599-606.

Cheng, G.W. and P.J. Breen. 1992. Cell count and size in relation to fruit size among strawberry cultivars. J. Amer. Soc. Hort. Sci. 117:946950.

Egli, D.B. and W.P. Bruening. 2006. Temporal profiles of pod production and pod set in soybean. Eur. J. Agron. 24:11-18.

Goldschmidt, E.E. 1999. Carbohydrate supply as critical factor for citrus fruit development and productivity. HortScience 34:1020-1024.

Gottschall, J. 2001. Paprika worstelt met pieken en dalen. Groenten \& Fruit 24:62-63.

Guilioni, L., J. Wéry, and F. Tardieu. 1997. Heat stress-induced abortion of buds and flowers in pea: Is sensitivity linked to organ age or to relations between reproductive organs? Ann. Bot. (Lond.) 80:159-168

Guitián, J., P. Guitián, and M. Medrano. 2001. Causes of fruit set variation in Polygonatum odoratum (Liliaceae). Plant Biol. 3:637-641.

Halbrecq, B., P. Romedenne, and J.F. Ledent 2005. Evolution of flowering, ripening and seed set in buckwheat (Fagopyrum esculentum Moench): Quantitative analysis. Eur. J. Agron. 23:209-224.

Heuvelink, E., L.F.M. Marcelis, and O. Körner. 2004. How to reduce yield fluctuations in sweet pepper? Acta Hort. 633:349-355.

Jasso-Chaverria, C., G.J. Hochmuth, R.C. Hochmuth, and S.A. Sargent. 2005. Fruit yield, size, and color responses of two greenhouse cucumber types to nitrogen fertilization in perlite soilless culture. HortTechnology 15:565-571.

Kleinbaum, D.G. and M. Klein. 2005. Survival analysis, a self-learning text. 2nd Ed. Springer, New York, NY.

Lebon, G., E. Duchêne, O. Brun, C. Magné, and C. Clément. 2004. Flower abscission and inflorescence carbohydrates in sensitive and nonsensitive cultivars of grapevine. Sex. Plant Reprod. 17:71-79.

Marcelis, L.F.M. 1992. The dynamics of growth and dry matter distribution in cucumber. Ann. Bot. (Lond.) 69:487-492.

Marcelis, L.F.M. 1996. Sink strength as a determinant of dry matter partitioning in the whole plant. J. Expt. Bot. 47:1281-1291.

Marcelis, L.F.M., E. Heuvelink, L.R. Baan HofmanEijer, J. Den Bakker, and L.B. Xue. 2004. Flower and fruit abortion in sweet pepper in relation to source and sink strength. J. Expt. Bot. 55:2261-2268.

Passam, H.C. and E.M. Khah. 1992. Flowering, fruit set and fruit and seed development in two cultivars of aubergine (Solanum melongena $\mathrm{L}$.) grown under plastic cover. Scientia Hort. 51:179-185. 
R Development Core Team. 2007. R: A language and environment for statistical computing. R Foundation for Statistical Computing, Vienna, Austria.

Reed, A.J. and G.W. Singletary. 1989. Role of carbohydrate supply and phytohormones in maize kernel abortion. Plant Physiol. 91:986992.

Sassenrath-Cole, G.F. 1995. Dependence of canopy light distribution on leaf and canopy structure for two cotton (Gossypium) species Agr. For. Meteorol. 77:55-72.
Shifriss, C., M. Pilowsky, and B. Aloni. 1994. Variation in flower abscission of peppers under stress shading conditions. Euphytica 78:133-136.

Sokal, R.R. and F.J. Rohlf. 1994. Biometry: The principles and practices of statistics in biological research. 3rd Ed. Freeman, San Francisco, CA.

Stapleton, S.C., H.C. Wien, and R.A. Morse. 2000 Flowering and fruit set of pumpkin cultivars under field conditions. HortScience 35:10741077.
Turner, A.D. and H.C. Wien. 1994. Dry matter assimilation and partitioning in pepper cultivars differing in susceptibility to stress-induced bud and flower abscission. Ann. Bot. (Lond.) 73:617-622.

Zhang, C., K. Tanabe, F. Tamura, A. Itai, and S. Wang. 2005. Spur characteristics, fruit growth, and carbon partitioning in two late-maturing Japanese pear (Pyrus pyrifolia Nakai) cultivars with contrasting fruit size. J. Amer. Soc. Hort Sci. 130:252-260. 